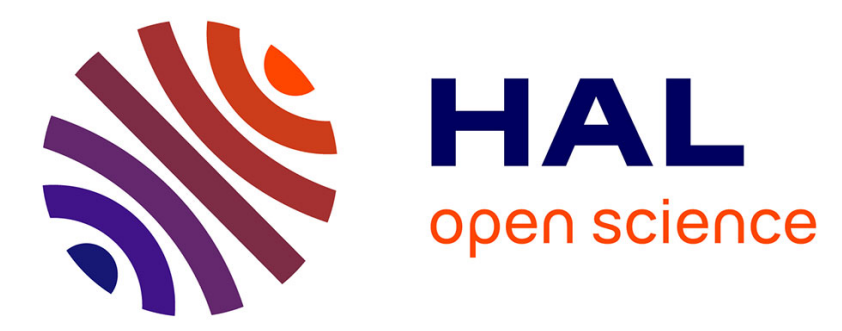

\title{
Multiaxial fatigue under complex non-relaxing loads
}

I. Warneboldt, F. Szmytka, I. Raoult, Yann Marco, V. Le Saux, P. Charrier, C. Champy, W. Hervouet

\section{To cite this version:}

I. Warneboldt, F. Szmytka, I. Raoult, Yann Marco, V. Le Saux, et al.. Multiaxial fatigue under complex non-relaxing loads. 11th European Conference on Constitutive Models for Rubber (ECCMR 2019), Jun 2019, Nantes, France. 10.1201/9780429324710-74 . hal-02304559

\section{HAL Id: hal-02304559 \\ https://hal-ensta-bretagne.archives-ouvertes.fr/hal-02304559}

Submitted on 17 Jun 2021

HAL is a multi-disciplinary open access archive for the deposit and dissemination of scientific research documents, whether they are published or not. The documents may come from teaching and research institutions in France or abroad, or from public or private research centers.
L'archive ouverte pluridisciplinaire HAL, est destinée au dépôt et à la diffusion de documents scientifiques de niveau recherche, publiés ou non, émanant des établissements d'enseignement et de recherche français ou étrangers, des laboratoires publics ou privés.

\section{(c)(1)}

Distributed under a Creative Commons Attribution| 4.0 International License 


\title{
Multiaxial fatigue under complex non-relaxing loads
}

\author{
I. Warneboldt \\ Vibracoustic Nantes, CAE \& Durability Prediction Department, Carquefou, France \\ ENSTA Bretagne, UMR CNRS 6027, IRDL, Brest, France \\ F. Szmytka \\ ENSTA ParisTech, IMSIA - UMR EDF/CNRS/CEA/ENSTA 9219, UME, Palaiseau, France
}

I. Raoult

Groupe PSA, Scientific and Future Technologies Department, Vélizy-Villacoublay, France

Y. Marco \& V. Le Saux

ENSTA Bretagne, UMR CNRS 6027, IRDL, Brest, France

P. Charrier, C. Champy \& W. Hervouet

Vibracoustic Nantes, CAE \& Durability Prediction Department, Carquefou, France

\begin{abstract}
Automotive anti-vibration parts undergo complex and multi-directional fatigue loadings, which must be considered and finally validated in their design phase. Some parts have to endure Road Load Data (RLD) test-loads (i.e. stochastic signals, representative for the actual service conditions of a part), meanwhile being already pre-charged by a constant load e.g. by the engine mass or by swaging. These conditions might result in positive minimal load values. For natural rubber, it is well known that this leads to material reinforcement which is usually related to strain induced crystallization. The reinforcement effect is well studied and illustrated in the so-called Haigh diagram by various previous studies of uni-axial tension tests Cadwell et al. 1940, Champy et al. 2015). However, to be able to determine a mean-load correction factor for a part or a specimen under complex stochastic loads, the concept of the Haigh diagram must be extended to various complex and multi-axial test conditions. It is crucial for its fundamental understanding to perform a dedicated experimental test campaign on specimens under different complex periodic loading cycles. Such fatigue tests are conducted on hourglass-shaped natural rubber specimens, loaded by coupled and aligned tension and torsion actuators, which permits to induce numerous complex load states. Finite Element Analysis (FEA) is used to determine the respective local mechanical state in the rubber specimens. Different strain, biaxiality ratio and critical plane orientation histories over a loading cycle are achieved in different test series. Finally, the number of cycles to crack-initiation and the final fracture surfaces are carefully analyzed using an optical microscope and a Scanning Electron Microscope (SEM). The results are then compared with the outcomes of non-relaxing fatigue tests in simple tension and torsion with the same specimens.
\end{abstract}

\section{INTRODUCTION}

Even though, several works are published concerning multiaxial fatigue of natural rubber parts (Le Cam 2005, Saintier et al. 2006, Ostoja-Kuczynski 2005) as well as the reinforcement effect (Cadwell et al. 1940, Champy et al. 2015), only a few known publications address a combination of both (Mars 2001, Saintier 2000). Our final target of a comprehensive test campaign is to understand the fatigue behavior and the damage mechanisms of a specimen which is undergoing complex and non-relaxing loadings. One experimental setup combines an alternating rotation load with a constant pre-displacement of the sample. After describing the specimen and the testing conditions, we will present the experimental outcomes and discuss the results.

\section{METHODS}

\subsection{Material and samples}

The studied rubber-like material is based on natural rubber. The specimens were manufactured under equal molding settings and from a single material batch to ensure the same mixing conditions. Their geometry is given in Figure 1. The advantage of the axisymmetric, notched specimen is the fact that it has a well-defined and limited zone of fatigue crack initiations in the notch ground. The low tested volume also reduces the heat build-up during fatigue tests. 


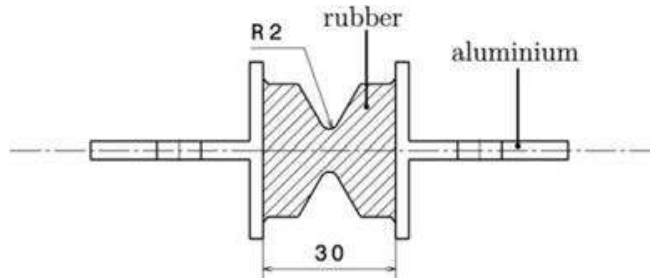

Figure 1. AE2 specimen geometry.

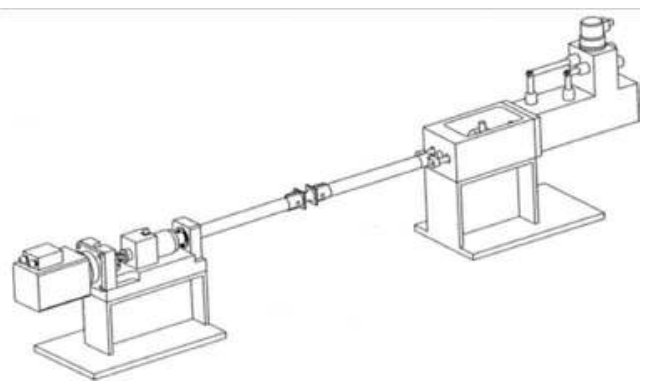

Figure 2. Test rig of coupled rotation and displacement actuators. The climate chamber is not shown.

\subsection{Experimental Setup}

The experiments are conducted with the test configuration shown in Figure 2. The electrical rotation and pneumatic displacement actuators are aligned and coupled. The tests are driven in a displacement/ rotation-controlled manner, while the reaction force and torque are constantly recorded. The climatic chamber that surrounds the tested sample guarantees a constant air temperature of $23 \mathrm{C}$. An infrared sensor pointing at the specimens notch ground is measuring its surface temperature. To ensure a similar material heat build-up, the frequency of the cyclic load is tuned to have a surface temperature of approx. $30^{\circ} \mathrm{C}$. The presented experiments are conducted with a rotation frequency of 0.8 to $2 \mathrm{~Hz}$.

While setting six fixed pre-displacement levels between $0 \mathrm{~mm}$ and $11 \mathrm{~mm}$ to the specimen, we apply

Table 1. Tested rotation/displacement loads.

\begin{tabular}{lllll}
\hline Load-level & $\begin{array}{l}\text { Fixed displ. } \\
(\mathrm{mm})\end{array}$ & $\begin{array}{l}\text { Min } \\
\text { rotation } \\
\text { angle }\left(^{\circ}\right)\end{array}$ & $\begin{array}{l}\text { Max } \\
\text { rotation } \\
\text { angle }\left(^{\circ}\right)\end{array}$ \\
\hline Relaxing & & 0 & 0 & 150 \\
Alternating & 0 & 0 & -150 & 150 \\
& 1 & 1 & -150 & 150 \\
& 2 & 2.5 & -150 & 150 \\
& 3 & 5 & -150 & 150 \\
& 4 & 8.5 & -150 & 150 \\
& 5 & 11 & -150 & 150 \\
\hline
\end{tabular}

a sinusoidal alternating rotation of \pm 150 . For further discussions, we will also present the results of a relaxing load-level, at which the samples were fixed at $0 \mathrm{~mm}$ displacement and loaded with relaxing rotation cycles. All tested load-levels are listed in Table 1. We conducted tests on four samples per load-level.

\section{RESULTS AND DISCUSSIONS}

\subsection{Results}

The number of cycles to crack initiation $N i$ are determined by the $N . d k / d N$ criterion introduced in OstojaKuczynski et al. 2003. The evaluated torsional stiffness is used for the criterion, because the rotation is the imposed cyclic load. Typical evolutions of the criterion and of the respective stiffness amplitude history are given in Figure 3. The derived results for $\mathrm{Ni}$ are given in Figure 4 as a plot over the experimental fixed displacement.

Figure 5 gives the actual imposed angle/displacement evolutions and the respective reaction force vs

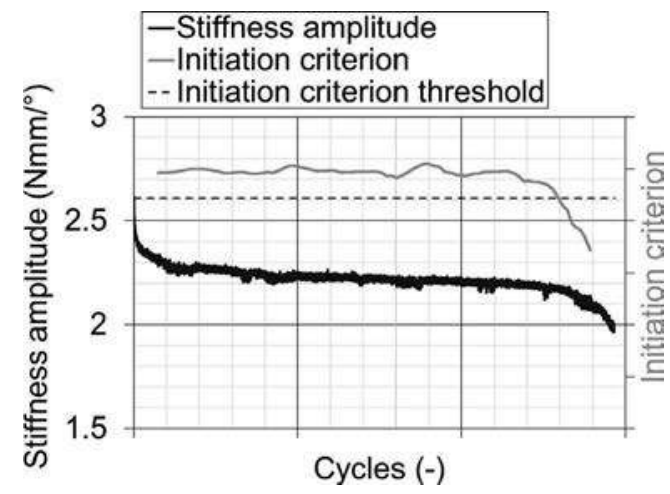

Figure 3. Crack initiation criterion evolution and torsional stiffness amplitude.

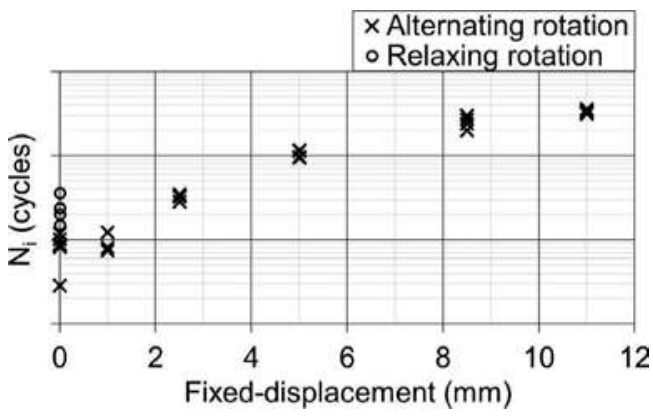

Figure 4. Derived number of cycles for all tested samples given over the fixed pre-displacement during experiments. 

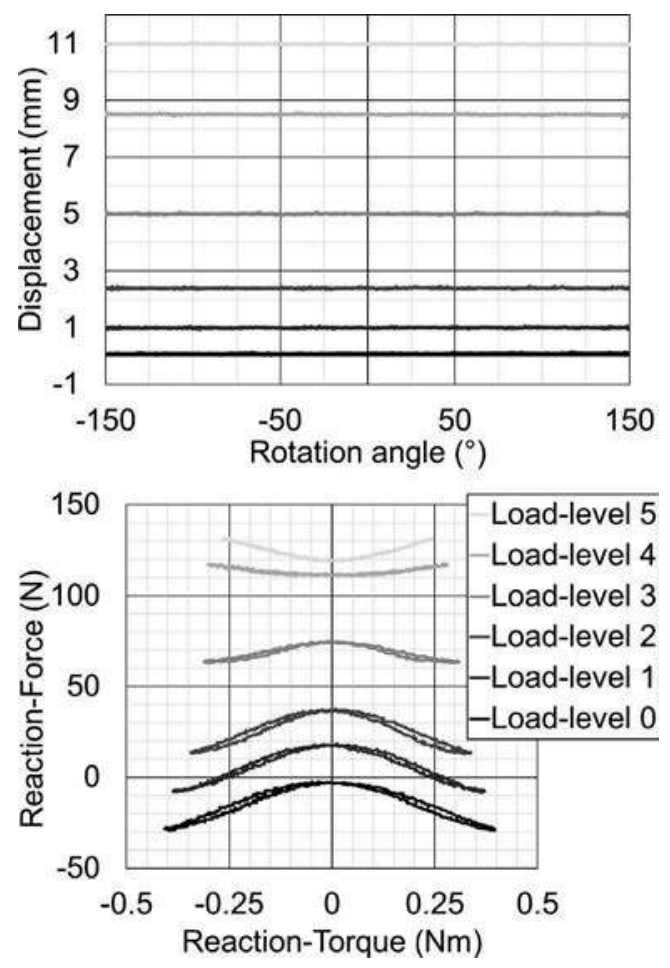

Figure 5. Diagrams of the imposed displacement over the alternating rotation angle (upper) and of the recorded outer reaction force over the reaction torque (lower).

torque curves of one representative load-cycle (at approx. $50 \%$ of $\mathrm{Ni}$ ) for each of the alternating load levels.

For the SEM analyses of the sample surfaces, the metallic inserts are clamped to a dedicated mount to assure a well-controlled alignment. We analyze each sample from four sides. The crack orientation angle is measured for all cracks in the small area which is almost orthogonal to the viewpoint. An accurate angle determination outside this region is not possible because cracks are distorted on the images due to the lens perspective. The derived orientation angles are defined with regard to a horizontal line (parallel to the radial direction of the specimen).

The scattering of the measured angles is expressed by giving the empirical standard deviation. The angle measures are given in Table 2. Images of post-experimental sample surfaces from SEM analyses are presented for each of the tested load-levels in Figure 6.

The six tests under alternating rotation (Figure $6 \mathrm{~b}$ to g), can be grouped according to two different kinds of crack shapes. The fatigue cracks on sample surfaces from load-level 0 and 1 (Figure $6 \mathrm{~b}$ and $\mathrm{c}$ ) have relatively grainy crack edges, although the loadlevel 1 samples have cleaner edges. These cracks do not have a clear orientation but are rather horizontal. In the contrary, the samples from load-level 2 to 5 (Figure $6 \mathrm{~d}$ to $\mathrm{g}$ ) have quite sharp crack edges and
Table 2. Determined angle measures for each load-level

\begin{tabular}{|c|c|c|c|c|c|}
\hline \multicolumn{2}{|l|}{ Load-level } & \multicolumn{2}{|c|}{$\begin{array}{l}\text { Mean orientation } \\
\text { angle }\left({ }^{\circ}\right)\end{array}$} & \multicolumn{2}{|c|}{$\begin{array}{l}\text { Empirical standard } \\
\text { deviation }\left(^{\circ}\right)\end{array}$} \\
\hline & & Positive & Negative & Positive & Negative \\
\hline \multirow{7}{*}{$\begin{array}{l}\text { Relaxing } \\
\text { Alternating }\end{array}$} & & - & -31.1 & - & 9.39 \\
\hline & 0 & \multicolumn{4}{|c|}{ Grainy, horizontal crack shapes } \\
\hline & 1 & \multicolumn{4}{|c|}{ Grainy, horizontal crack shapes } \\
\hline & 2 & 44.2 & -45.0 & 4.59 & 3.51 \\
\hline & 3 & 64.1 & -62.0 & 4.71 & 5.73 \\
\hline & 4 & 72.6 & -68.1 & 4.71 & 5.73 \\
\hline & 5 & 73.6 & -75.2 & 3.47 & 3.64 \\
\hline
\end{tabular}

most of them are oriented in one of the two principal directions. These directions are symmetric to each other in reference to the vertical axis, as also shown by the measured angles (Table 2). The relaxing rotation tests with a fixed displacement at $0 \mathrm{~mm}$ only cause negative crack orientation angles (Figure 6a). The crack edges seem also rather grainy and their orientations are more scattered than for the alternating rotation experiments (see Table 2).

Looking at the determined number of cycles to crack initiation (Figure 4), one can clearly see a reinforcement effect. Higher fixed displacements result in increased lifetimes. The alternating tests with $0 \mathrm{~mm}$ displacement result in significant lower lifetimes than the ones with relaxing rotation cycles.

\subsection{Discussions}

\subsubsection{Discussion on the two principal crack orientations}

For the load-levels 2 to 5 with alternating rotations, cracks are mostly oriented in one of two principal

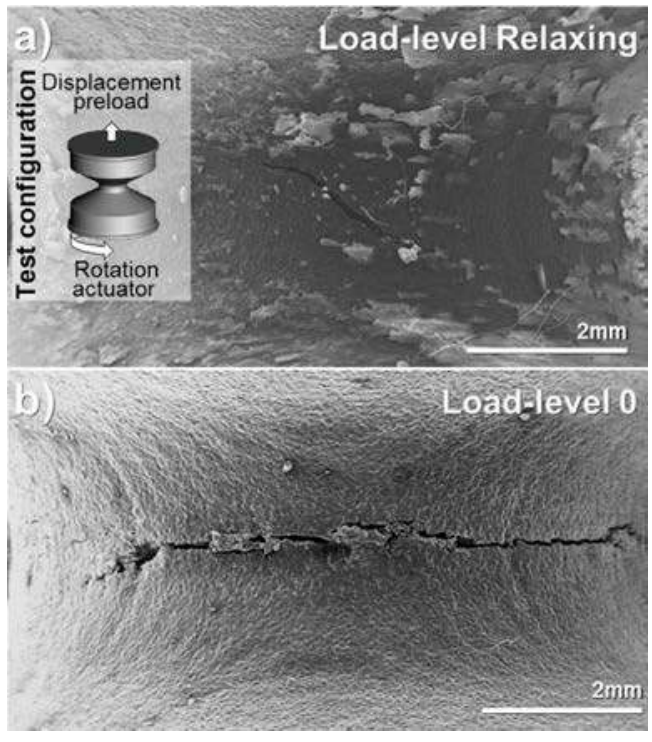



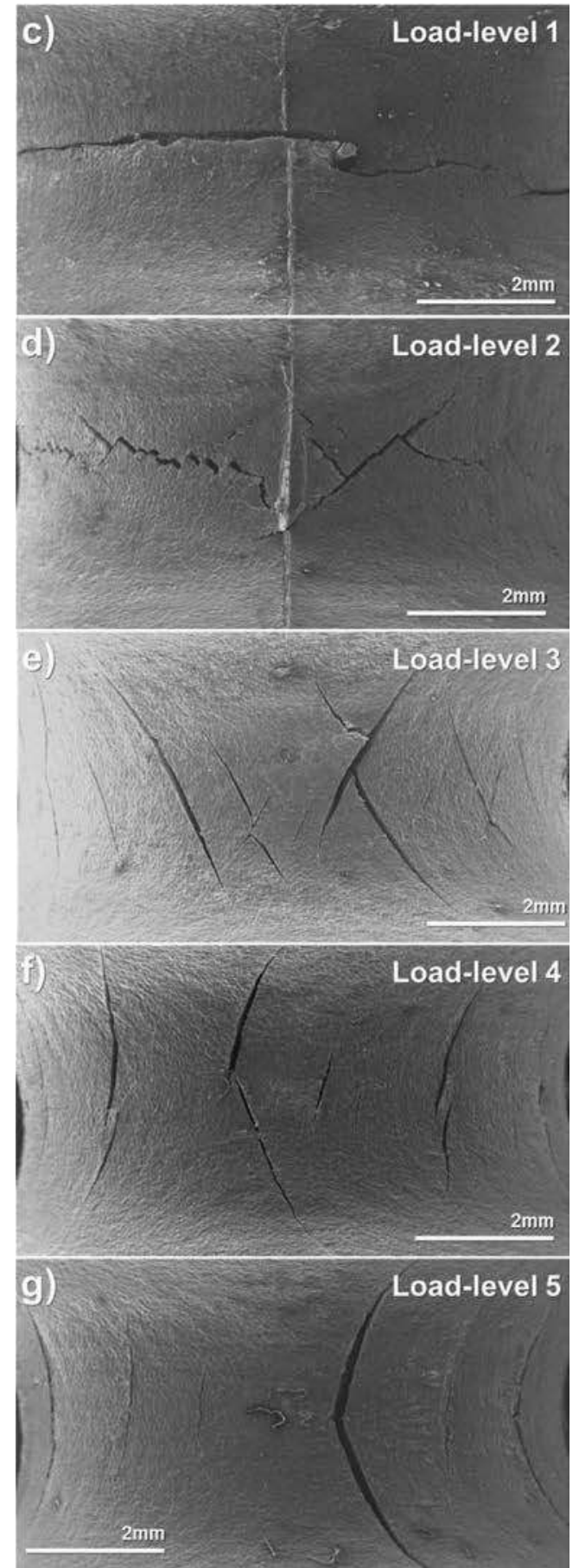

Figure 6. Images of the post-experimental sample surfaces taken by a SEM.

directions (see Figure 6d to g). A closer look to cracks with rather horizontal alignment e.g. at a loadlevel 2 sample (see Figure 7) shows that these cracks

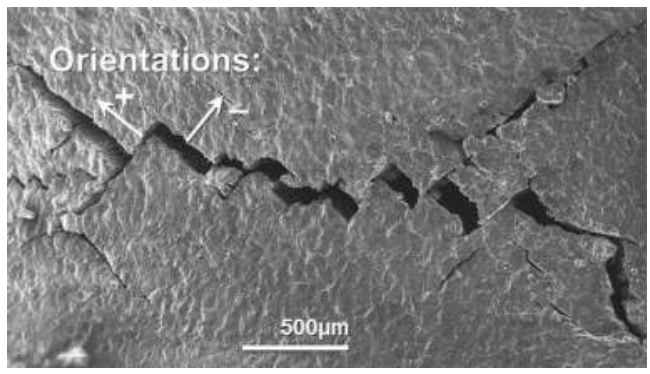

Figure 7. A closer view of the load-level 2 sample surface shown in Fig 6d.
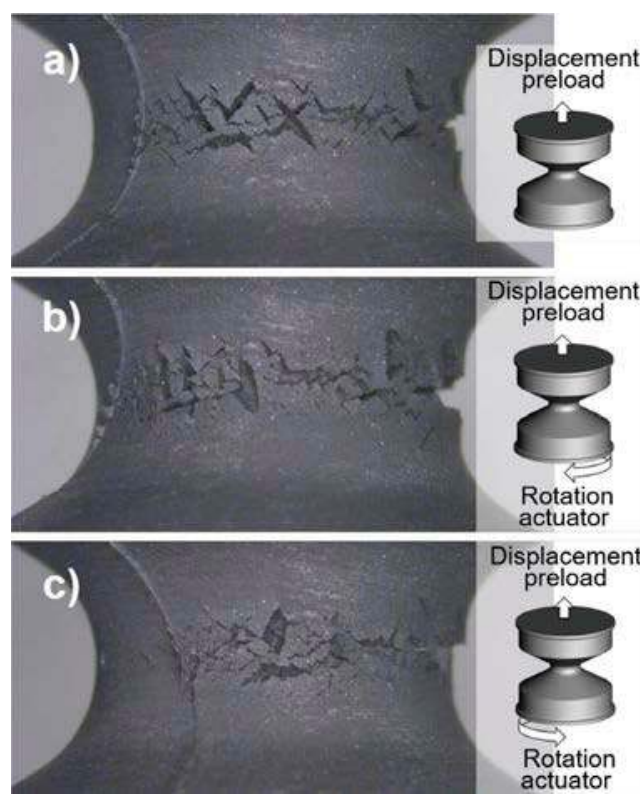

Figure 8. Images of a level 2 sample surface under a) the displacement preload, b) the displacement preload and positive rotation, c) the displacement preload and negative rotation.

also propagate either in the positive or the negative principal direction.

An explanation for the two principal orientations might be the alternating rotation cycles. They can be divided at the zero rotation crossings in two halfcycles. Each of the half cycles goes from zero rotation to the positive or negative extreme point of the rotation. While the half cycle in positive rotation is opening the cracks, which are orientated in the negative principal orientation, the negative half cycle does the opposite. Figure 8 is showing this for one sample.

Therefore, the positive half cycle of the rotation causes notably damage in the material planes which are oriented in the negative principal direction. The 


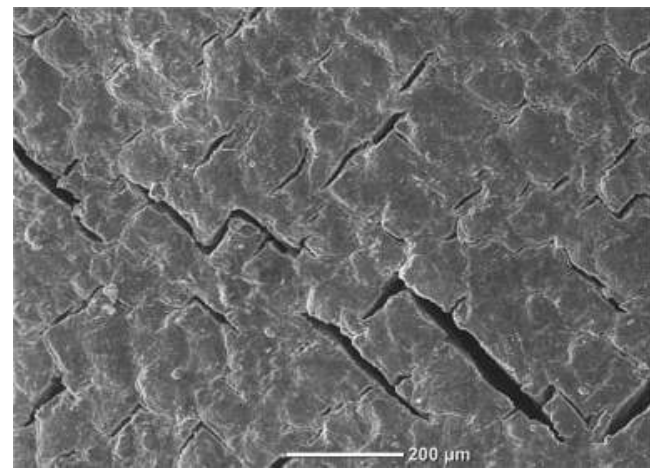

Figure 9. A load-level 2 sample surface with high magnification.

negative half-cycle is respectively most notably responsible for the cracks with a positive orientation. The vertical symmetry of the observed principal crack orientations is supporting this hypothesis, since the two half cycles in rotation have the same symmetry axis. Once a micro-crack propagated in one of the two principal directions, the corresponding half cycles would cause most of the further propagation while the opposite half cycles close the crack. Figure 9 shows that even very small cracks with a length of less than $100 \mu \mathrm{m}$ orient in one of the two principal directions.

\subsubsection{Discussion on the two kind of crack appearances}

A remarkable difference for the two groups separated by the crack appearance (load-levels 0 to 1 on one side, load-levels 2 to 5 on the other side) are the reaction-force/reaction-torque curves given in Figure 5. While the first group (with grainy, horizontal crack shapes) experiences negative outer reaction forces during a rotational cycle, the second group is only loaded by positive outer loads. A negative outer force causes a compression reaction for the specimen, whereas the positive outer forces cause tension. While the tension of the fatigue sample would rather open some initiated micro cracks, the compression state would close them and press the crack surfaces together. The added outer rotation of the sample causes these surfaces to slide against each other. This leads to friction and due to the compression possibly to abrasion. The grainy crack edges sustain this hypothesis.

Meanwhile, it might as well give the explanation for the mostly horizontal crack orientations. The microscopic crack surfaces most notably slide against each other both at the positive half-cycle and the negative half cycle of the rotation due to the material compression in vertical direction. The friction and material abrasion might cause an initiated crack to propagate with each half-cycle which can explain the vague zigzag patterns. With the material

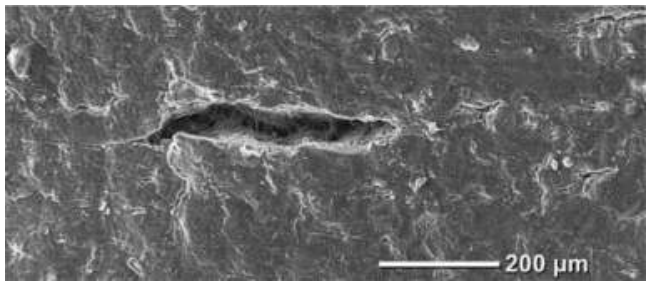

Figure 10. A load-level 2 sample surface with high magnification.

abrasion, these patterns might appear to be horizontal. Figure 10 shows a crack of $200 \mu \mathrm{m}$ length with high magnification.

The relaxing rotation tests with $0 \mathrm{~mm}$ displacement cause fatigue cracks which are almost all with a negative orientation angle, even though the samples also experience negative outer loads. No cracks with positive orientation angles are observed. This supports the hypothesis that the horizontal cracks of the load-level 0 and 1 must also propagate in both principal orientations in zigzag patterns. As already mentioned, the samples durability for the relaxing rotation tests is significantly increased compared to the alternating load-level 0 . The shorter lifetime could be caused by a faster propagation of microcracks because they propagate during both halfcycles of the alternating rotation.

\section{OUTLOOK}

The presented test results clearly point out the necessity of further tests and devoted FEA under similar conditions to understand the observed crack growth orientations as well as the different crack appearances for load-levels 0 to 1 and load-levels 2 to 5 .

We will conduct a dedicated test in which the load-levels 1 to 5 will be repeated with the same fixed displacements but with returning rotation conditions (0 to max. rotations). Therefore, only the positive rotation will be enforced. A study of the resulting number of cycles to crack initiation and the orientation angles will allow a comprehensive comparison with the currently discussed study.

A comparison of the lifetimes and the negative crack orientation angles for experiments with equal fixed displacements and relaxing, respectively alternating, rotation conditions will support our comprehension of the fatigue scenarios of load-level 2 to 5 .

Further experiments with fixed displacements that cause a compression state of the sample during alternating rotation cycles will also be performed. Interrupted fatigue tests with SEM analyses as well as micro-computer tomography scans at early fatigue states are anticipated. This will help us to further understand the respective damage mechanisms. 


\section{ACKNOWLEDGEMENT}

The authors would like to thank ANRT for its financial support.

\section{REFERENCES}

Cadwell, S., R. Merrill, C. Sloman, \& F. Yost (1940). Dynamic fatigue life of rubber. Industrial and Engineering Chemistry 12(1),19-23.

Champy, C., V. Le Saux, Y. Marco, P. Charrier, \& W. Hervouet (2015). On the use of a full haigh diagram for lifetime prediction of rubber parts. In B. Marvalová and I. Petríková (Eds.), Constitutive models for rubber IX, London, pp. 551-557.

Le Cam, J.-B. (2005). Endommagement en fatigue des élastoméres. Phd thesis, Ecole Centrale de Nantes (ECN).
Mars, W. (2001). Multiaxial fatigue of rubber. Phd thesis, University of Toledo.

Ostoja-Kuczynski, E. (2005). Comportement en fatigue des élastoméres: application aux structures antivibratoires pour l'automobile. Phd thesis, Ecole Centrale de Nantes (ECN).

Ostoja-Kuczynski, E., P. Charrier, E. Verron, G. Marckmann, L. Gornet, \& G. Chagnon (2003). Crack initiation in filled natural rubber: experimental database and macroscopic observations. In J. Busfield and A. Muhr (Eds.), Constitutive models for rubber III, London, pp. 41-47.

Saintier, N. (2000). Prévisions de la durée de vie en fatigue $d u$ NR, sous chargement multiaxial. Phd thesis, Ecole des Mines de Paris.

Saintier, N., G. Cailletaud, \& R. Piques (2006). Crack initiation and propagation under multiaxial fatigue in a natural rubber. International Journal of Fatigue 28 (1), 61-72. 